\title{
Development of High Performance Multifilamentary Nb-Ti-Ta Superconductor for LHC Insertion Quadrupoles
}

\author{
P. J. Lee ${ }^{\dagger}$, C. M. Fischer, D. C. Larbalestier*, M. T. Naus, A. A. Squitieri, W. L. Starch, and R. J. Werner \\ Applied Superconductivity Center, University of Wisconsin-Madison, Madison WI 53706, USA \\ P. J. Limon, G. Sabbi, and A. Zlobin \\ Fermi National Accelerator Laboratory, Batavia IL, USA \\ E. Gregory \\ IGC Advanced Superconductors, Waterbury CT, USA
}

\begin{abstract}
A preliminary investigation of a new $\mathrm{Nb}-\mathrm{Ti}-\mathrm{Ta}$ $(39 \mathrm{wt} \% \mathrm{Nb}, 44 \mathrm{wt} . \% \mathrm{Ti}, 17 \mathrm{wt}$. \% Ta) alloy has been investigated as a possible material for application at $1.9 \mathrm{~K}$ and $10.5 \mathrm{~T}$ in the insertion quadrupoles of LHC. $1550 \mathrm{~A} / \mathrm{mm}^{2}$, the highest yet reported critical current density at $10.5 \mathrm{~T}(1.9 \mathrm{~K})$, was achieved in a monofilament of this material. The initial multifilamentary production strand produced a lower $10.5 \mathrm{~T}(1.9 \mathrm{~K})$ critical current density of $1370 \mathrm{~A} / \mathrm{mm}^{2}$. Large variations in precipitate size were produced in the microstructures, which have yet to be fully optimized. Quantitative analysis of the microstructures in a $\mathrm{Nb}$ $44 \mathrm{wt} . \% \mathrm{Ti}-15 \mathrm{wt} . \% \mathrm{Ta}$ alloy reveals a linear relationship between volume $\%$ of $\alpha$-Ti precipitate and critical current density at $5 \mathrm{~T}$ and $8 \mathrm{~T}(4.2 \mathrm{~K})$. The increase in critical current with precipitate volume is less than for $\mathrm{Nb}-47 \mathrm{wt}$. \% Ti. High resolution FESEM electron backscatter images suggest a high atomic number region adjacent to the grain boundaries after heat treatment.
\end{abstract}

\section{INTRODUCTION}

To obtain sufficiently high field gradients for the insertion quadrupoles of LHC requires a very compact magnet design operating at the very highest current densities possible. This translates in practice into the choice of a $\mathrm{Nb}-\mathrm{Ti}$ alloy based conductor operating at $1.8-1.9 \mathrm{~K}$. Such conductor is strong and ductile and the fabrication techniques are well established. A key issue for the present designs of low beta quads is how to make a conductor with the very best properties at 8-12 Tesla and $1.9 \mathrm{~K}$. At high field and low temperature there is relatively little data, and no systematic studies have been made in order to optimize the critical current density, $J_{c}$. A program was initiated at the Fermi National Accelerator Laboratory in order to develop an understanding of the behavior and potential of $\mathrm{Nb}-\mathrm{Ti}$ based strand at high field and low temperature.

Proposals were invited to develop Nb-Ti based strand with improved critical current, $I_{c}$, at $10.5 \mathrm{~T}$ and $1.9 \mathrm{~K}$ over existing SSCL designs using full-scale billets. Two routes were pursued, one using $\mathrm{Ta}$ alloying to increase the upper critical field, $H_{\mathrm{c} 2}$,

Mạnuscript received September $15^{\text {th }}, 1998$.

Funding for the University Of Wisconsin-Madison Applied Superconductivity Center's participation in this program was through US DOEHEP grant DE-FG02-91ER40643 and FNAL PO number B94240. This work also benefited from NSF-MRSEC DMR-9632427 supported facilities.

* Also the Department of Materials Science and Engineering.

† Email: lee@engr.wisc.edu. Internet: http://www.cae.wisc.edu/ plee/ and the other using Fe doping to improve the pinning efficiency density by modifying the microstructure. The high $\mathrm{Fe}$ work is reported on elsewhere [1].

$\mathrm{Nb}$-Ti alloys with Ta additions have an enhanced $H_{\mathrm{c} 2}$ at low temperature because the $\mathrm{Ta}$ atoms suppress the paramagnetic limitation. The effect is minor at $4.2 \mathrm{~K}$ but at $2 \mathrm{~K}$ there is an increase in $H_{\mathrm{c} 2}$ of 1-1.3 T [2], [3]. Nb-Ti-Ta alloys have the same ease of processing as binary Nb-Ti alloys [4], [5] but the alloy is more difficult to produce to high chemical homogeneity and is more expensive. The advantage in $H_{\mathrm{c} 2}$ has proven difficult to exploit in terms of current density at high field. Typically the best $\mathrm{Nb}$-Ti-Ta alloys have only outperformed the best $\mathrm{Nb}-\mathrm{Ti}$ strands at fields at or above $11 \mathrm{~T}(1.9-2 \mathrm{~K})[5]$, [6].

For binary $\mathrm{Nb}$ - $\mathrm{Ti}$ there is a well established linear relationship between the volume percent of $\alpha$-Ti precipitate produced in the microstructure and the peak $J_{c}$ [7], [8], [9]. An earlier study had shown that the $\alpha-\mathrm{Ti}$ precipitation rate in a $\mathrm{Nb}-44$ wt.\%Ti$15 \mathrm{wt} . \%$ Ta alloy could be higher than for the standard binary $\mathrm{Nb}$ $47 \mathrm{wt} . \% \mathrm{Ti}$ alloy but that the $J_{c}$ at $4.2 \mathrm{~K}$ was lower [10]. More recently a study of strand manufactured from $\mathrm{Nb}-45 \mathrm{wt} \% \mathrm{Ti}-$ $15 \mathrm{wt} . \% \mathrm{Ta}$ indicated that there was only a weak relationship between volume of precipitate and $J_{\mathrm{c}}$ at $5 \mathrm{~T}(4.2 \mathrm{~K})$ and none at all at $8 \mathrm{~T}$ [11]. In this study we expand on earlier $\mathrm{Nb}-44 \mathrm{Ti}-15 \mathrm{Ta}$ work by applying restricted heat treatments previously applied to binary material [7]. We also report on a preliminary examination of a new Nb-44 wt.\%Ti-17 wt.\%Ta alloy, introduced as a potential material for LHC application. In conjunction with this study, a third alloy, $\mathrm{Nb}-12$ wt.\%Ta-46 wt.\%Ti was also studied and is reported on elsewhere [12].

\section{EXPERIMENTAL PROCEDURE}

The strand manufacturer was required to supply samples to the University of Wisconsin-Madison Applied Superconductivity Center throughout processing following the successful procedure of the SSC Phase II Research and Development program [13]. The samples supplied were fully analyzed by the UW by light microscopy, high resolution field emission scanning electron microscopy (FESEM), and energy dispersive $x$-ray analysis (EDS). Initial heat treatment investigations have been performed at the UW and by the strand manufacturers with feedback provided to the manufacturers by the UW. Testing was performed at $1.9 \mathrm{~K}$ and $4.2 \mathrm{~K}$ by the UW. 


\section{A. Strand Design}

Although the strand diameter was based on the SSC inner specifications, $0.808 \pm 0.0025 \mathrm{~mm}$, the manufacturers were given more flexibility on filament diameter with filament diameters up to $10 \mu \mathrm{m}$ allowed. The $\mathrm{Cu}$ :Superconductor ratio was $1.30 \pm 0.1: 1$. The $\mathrm{Nb}$ diffusion barrier used for the $17 \mathrm{wt} \%$ Ta alloy was thinner than that used for SSC strand and only represented approximately $2 \%$ of the non-Cu cross-section.

\section{B. Alloy Composition}

The Nb-44 wt.\%Ti-15 wt.\% Ta alloy was manufactured by (Teledyne) Wah Chang. The $17 \mathrm{wt} . \%$ Ta alloy was manufactured by $\mathrm{H}$. C. Starck by plasma melting. An initial alloy was manufactured of Nb-41 wt\%Ti-29 wt.\%Ta ("NRC115R5"). The $12 \mathrm{wt} . \%$ Ta and $17 \mathrm{wt} . \%$ Ta alloys were remelts based on additions to this starting material.

\section{Heat Treatment}

Monofilamentary 17Ta rod was supplied to the UW in both cold worked and annealed conditions. Hardness measurements indicated that the cold worked rod had an estimated cold worked strain that was 2.7 higher than the annealed material. A full-scale multifilamentary billet was manufactured by IGC from the lower strain monofilament and was supplied to the UW at $25.4 \mathrm{~mm}$ diameter for subsequent processing. Three heat treatments of $40 \mathrm{hr}$ at $405^{\circ} \mathrm{C}$ were applied to the monofilaments and the multifilamentary composite with a cold work drawing strain of 1.15 between heat treatments. The estimated initial cold work strain in the monofilamentary rods at the first heat treatment size was 5 for the intermediate annealed monofilament and 7.7 for the cold worked monofilament. The estimated cold work strain of the $25.4 \mathrm{~mm}$ multifilamentary billet was estimated at 6 by hardness measurement. A strain of 6 would be sufficient to produce homogeneous precipitation [14] in binary material but ternary alloy has been reported to be more susceptible to the formation intragranular Widmanstätten than equivalent binary alloy [11]. The restricted heat treatment of the $\mathrm{Nb}-44 \mathrm{wt} . \% \mathrm{Ti}-15 \mathrm{wt} . \% \mathrm{Ta}$ alloy monofilament is illustrated in Fig 1.

\section{Microstructural Evaluation}

Starting alloy micro-homogeneity was assessed by the application of a composition-sensitive etch [15] to cross-sections prepared by standard metallographic techniques. The use of a composition-sensitive etch allows for a qualitative assessment of homogeneity of the full ingot cross-section and the selection of representative regions for quantitative analysis by EDS. Hardness testing was performed throughout the processing of the strand in order to monitor the strain condition [16]. The microstructures of the strands were imaged using a LEO 982 high resolution FESEM in electron backscatter mode using a $\mathrm{K}$. E. Developments Ltd. solid state detector. This system is capable of sub-4 nm resolution and is well suited to viewing and quantifying the microstructure before it is reduced in size by

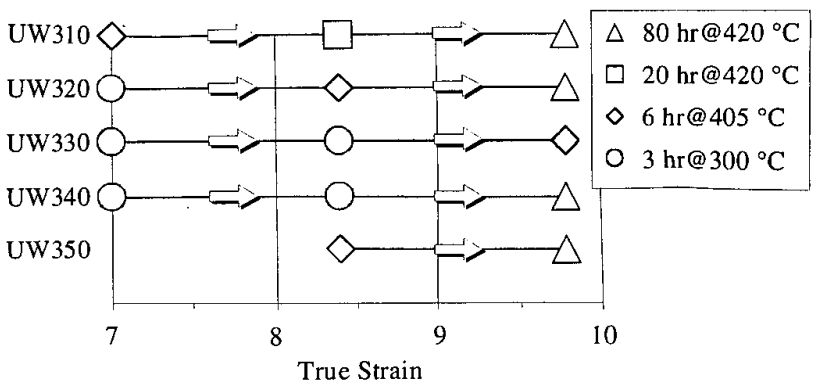

Fig 1. Schematic diagram illustrating the restricted heat treatment investigation of the $\mathrm{Nb}-\mathrm{Ti}-15 \mathrm{Ta}$ alloy monofilament.

final wire drawing. Images from the FESEM were quantified using Sigmascan Pro software by Jandel.

\section{E. Critical Current Measurement}

Strands for critical current testing were mounted on $25.4 \mathrm{~mm}$ diameter stainless steel mandrels, with the magnetic field perpendicular to the wire axis. Samples were tested in superfluid helium at $1.9 \mathrm{~K} \pm 30 \mathrm{mK}$. Temperature control was achieved using a manometer calibrated with a Cernox temperature sensor. The voltage tap spacing was $22.5 \mathrm{~cm}$ and à $10^{-14} \Omega \mathrm{m}$ criterion was applied across the entire wire cross-section to determine $I_{c} . J_{c}$ was calculated using the superconducting cross-sectional area. The error in magnetic field homogeneity was less than $1 \% .4 .2 \mathrm{~K}$ testing on the same strands was performed at atmospheric pressure with a temperature variation of less than $10 \mathrm{mK}$. Additional samples tested during initial optimization experiments at $4.2 \mathrm{~K}$ were mounted on standard $35 \mathrm{~mm}$ diameter stainless steel mandrels. The $J_{\mathrm{c}}$ values for the $\mathrm{Nb}-\mathrm{Ti}(\mathrm{Fe})$ strands were compared with three representative SSC production inner strands.

\section{Results}

\section{A. Alloys}

The chemical homogeneity of the alloys was very good and no freckling was observed in the as-received cross-sections, which had uniform grain and coring substructures. In Table 1 we compare the compositions and the local chemical composition and homogeneity of the base alloys.

The remelted $17 \mathrm{wt} . \% \mathrm{Ta}$ alloy was not quite as homogeneous as the base $29 \mathrm{wt} . \%$ Ta alloy. The composition sensitive etch revealed isolated areas with larger variations. EDS analysis quantified the Ti variation in those regions as $41-49 \mathrm{wt} . \%$ and the Ta variation from $22-15 \mathrm{wt} . \%$. The perturbations occurred over a distance of $\sim 1 \mathrm{~mm}$ and were separated by $5-10 \mathrm{~mm}$.

TABLE 1

LOCAL ALLOY COMPOSTTIONS

\begin{tabular}{lllllll}
\hline & \multicolumn{2}{l}{ NRC 115R5 } & \multicolumn{4}{c}{ Wah Chang 15Ta } \\
\cline { 2 - 7 } & $\mathrm{Nb}$ & $\mathrm{Ti}$ & $\mathrm{Ta}$ & $\mathrm{Nb}$ & $\mathrm{Ti}$ & $\mathrm{Ta}$ \\
\hline Mean, wt.\% & 30.2 & 40.7 & 29.1 & 42.2 & 44.3 & 13.4 \\
Std. Dev., wt.\% & 0.5 & 0.8 & 1.0 & 0.4 & 0.8 & 0.6 \\
Coeff. Var, \% & 1.5 & 1.9 & 3.3 & 1.0 & 1.9 & 4.7 \\
\hline
\end{tabular}




\section{B. Critical Current Density}

The initial results from the $\mathrm{UW}$-processed monofilament given $3 \times 40 \mathrm{hr}$ at $405^{\circ} \mathrm{C}$ heat treatments were very promising. At $10.5 \mathrm{~T}$, a $J_{\mathrm{c}}$ of $1550 \mathrm{~A} / \mathrm{mm}^{2}$ was attained using the monofilament that had not been annealed before heat treatment. This is the highest reported $J_{c}$ for any ductile superconductor at $10.5 \mathrm{~T}(1.9 \mathrm{~K})$. The results from the annealed and non-annealed strands are shown in Fig. 2. The strands manufactured from the cold worked monofilament had better $J_{\mathrm{c}}$ values up to $12 \mathrm{~T}(1.9 \mathrm{~K})$, whereas the monofilaments with the intermediate anneal performed better above $12 \mathrm{~T}(1.9 \mathrm{~K})$. The increase in field, at constant $J_{\mathrm{c}}$, obtained by reducing the temperature from $4.2 \mathrm{~K}$ to $1.9 \mathrm{~K}$, was $3.5 \mathrm{~T}$.

The restricted heat treatment series applied to the $\mathrm{Nb}-44$ wt.\%Ti-15 wt.\% Ta alloy further improved $J_{\mathrm{c}}$ at high field, as shown in Fig. 3, although the Nb-37wt.\%Ti-22wt.\%Ta based strands of Lazarev et al. [6] have higher $J_{\mathrm{c}}$ values above $11 \mathrm{~T}$ (Fig. 3). The initial production strand produced from the annealed monofilaments produced a lower $10.5 \mathrm{~T}(1.9 \mathrm{~K}) J_{\mathrm{c}}$ of only $1370 \mathrm{~A} / \mathrm{mm}^{2}$.

\section{Microstructures}

The initial heat treatments on the $\mathrm{Nb}-\mathrm{Ti}-17 \mathrm{wt} . \% \mathrm{Ta}$ strand produced microstructures with large variations in $\alpha$-Ti precipitate size. In particular the intermediate annealed monofilament heat treated at an estimated prestrain of 5 did not have the well-developed equiaxed transverse-cross-sectional microstructure that is normally expected at this prestrain [17]. The resulting inhomogeneous distribution of precipitates was still evident after the final precipitation heat treatment. Fine scale intragranular Widmanstätten precipitation was observed in the strand heat treated with an estimated prestrain of 7 as well as the strand made from the intermediate anneal rod. For the higher prestrain material, multiple heat treatment removed

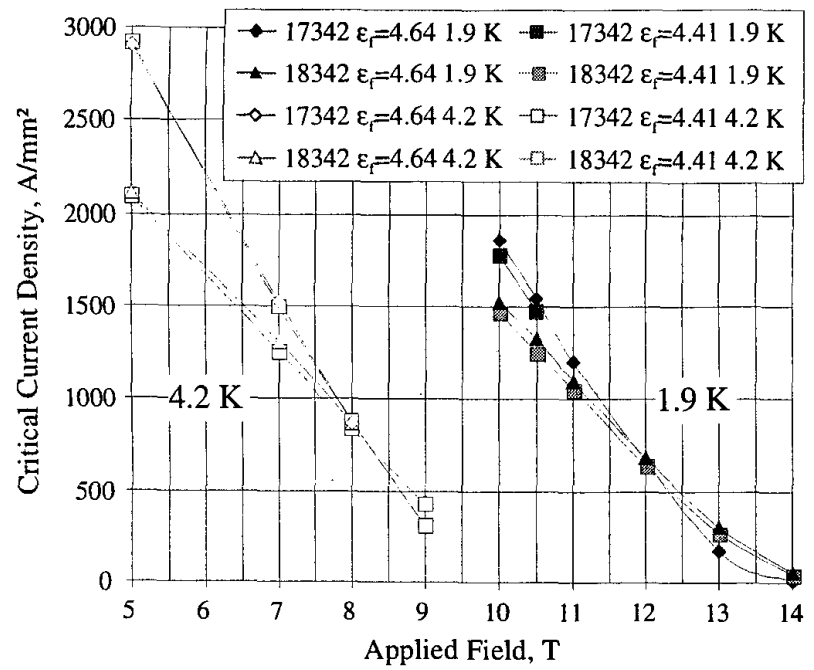

Fig. 2 Critical current densities at $4.2 \mathrm{~K}$ and $1.9 \mathrm{~K}$ for $39 \mathrm{wt} \% \mathrm{Nb}-44 \mathrm{wt} . \% \mathrm{Ti}-$ $17 \mathrm{wt} . \%$ Ta monofilament processed at the UW. The UW17343 series used cold worked monofilament, the 183432 series used monofilament that had received an intermediate anneal. Both strands received $3 \times 40 \mathrm{hr}$ at $405^{\circ} \mathrm{C}$ heat treatments.

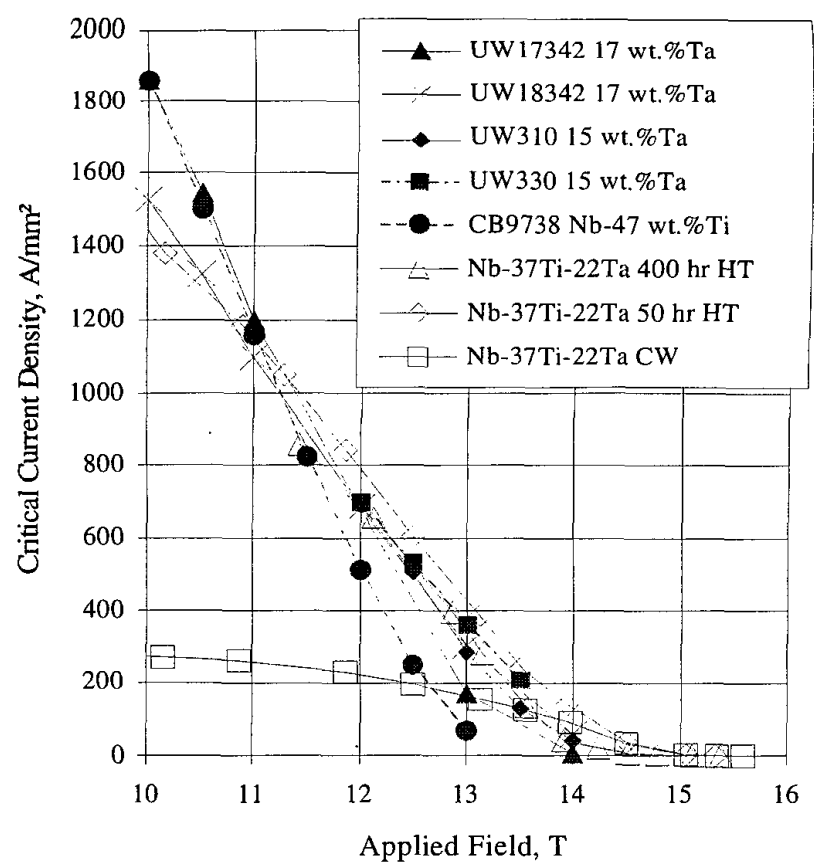

Fig. 3. A comparison, at high field, of the $1.9 \mathrm{~K}$ critical current densities reported here, with the $\mathrm{Nb}-37 \mathrm{Ti}-22 \mathrm{Ta}$ of Lazarev et al. [6] at $2.05 \mathrm{~K}$.

much of the inhomogeneity and resulted in a large volume of precipitate (29 volume \% compared with 18 volume \% for the low prestrain material). The distributions in the precipitate sizes are contrasted in Fig. 4 (for transverse cross-sections).

The $J_{\mathrm{c}}$ at $5 \mathrm{~T}(4.2 \mathrm{~K})$ and $8 \mathrm{~T}(4.2 \mathrm{~K})$ is shown as a function of measured volume \% of precipitate for the $\mathrm{Nb}-44$ wt.\%Ti-15 wt.\% Ta series in Figure 5. A linear relationship is shown with increasing $J_{\mathrm{c}}$ as the volume $\%$ of precipitate is increased. This relationship is observed at both $5 \mathrm{~T}$ and $8 \mathrm{~T}$ (whereas the previous work or Taillard et al. [11] suggested no increase in $J_{\mathrm{c}}$ at $8 \mathrm{~T}(4.2 \mathrm{~K})$ for $\left.\mathrm{Nb}-\mathrm{Ti}-15 \mathrm{wt} . \% \mathrm{Ta}\right)$. The gradient of the curve, however, is significantly lower than for the binary $\mathrm{Nb}-47 \mathrm{wt}$.\% Ti binary alloy.

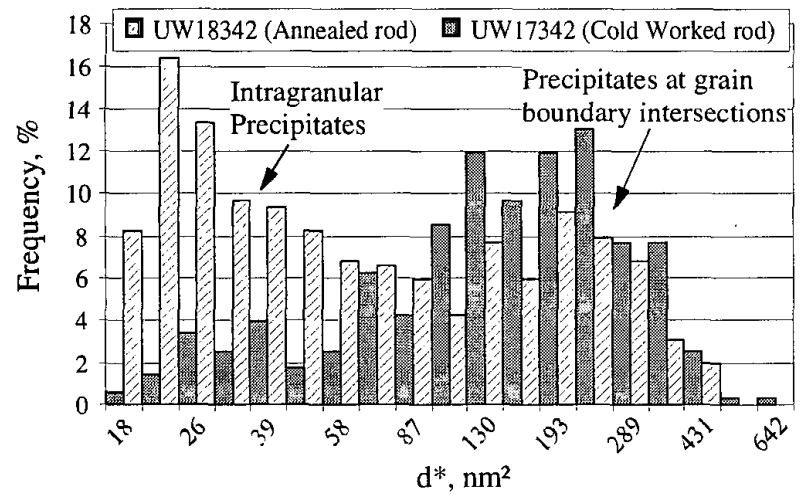

Fig. 4. Precipitate size distribution after $3 \times 40 \mathrm{hr}$ at $405^{\circ} \mathrm{C}$ heat treatments for UW17342 and UW18342. By using a log scale, the binomial precipitate size distribution can be observed, especially for UW 18342 which was heat-treated at a lower effective prestrain resulting in more intragranular precipitates. 


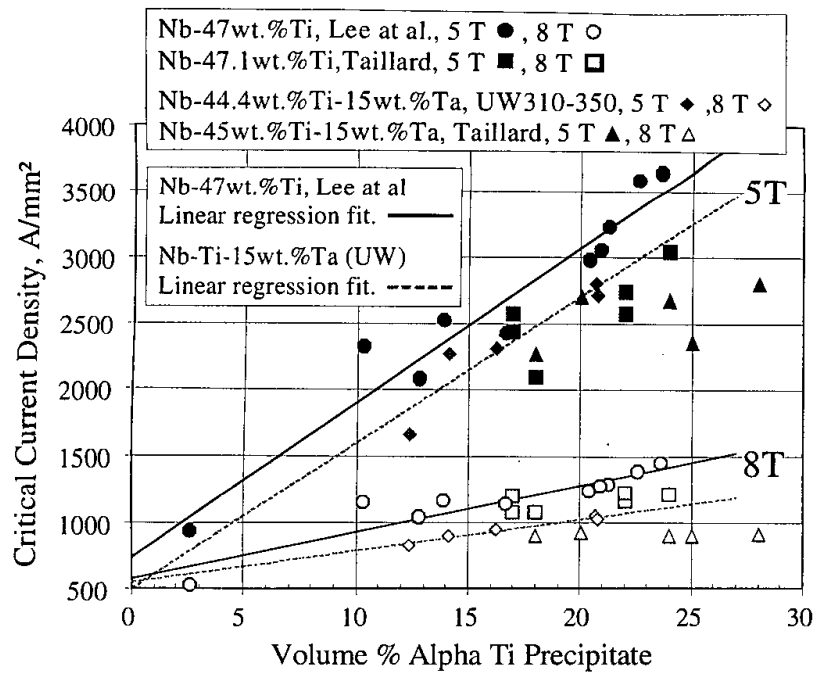

Figure 5. $J_{\mathrm{c}}$ at $4.2 \mathrm{~K}$ as a function of measured volume percent of $\alpha-\mathrm{T}$ precipitate for $\mathrm{Nb}-44 \mathrm{wt} . \% \mathrm{Ti}-15 \mathrm{wt} . \% \mathrm{Ta}$ in this study and previous analyses of $\mathrm{Nb}-47 \mathrm{wt} . \% \mathrm{Ti}[8]$ and $\mathrm{Nb}-\mathrm{Ti}-15 \mathrm{wt} . \% \mathrm{Ta}$ [11]

The high resolution FESEM backscattered electron images indicated regions of higher atomic number at the grain boundaries after heat treatment. The regions ranged in thickness from approximately $15-60 \mathrm{~nm}$. The contrast appeared to be greater than that observed in $\mathrm{Nb}-\mathrm{Ti}$ and $\mathrm{Nb}-\mathrm{Ti}(\mathrm{Fe})$ [1]. Heat treatment at high temperature $\left(475^{\circ} \mathrm{C}\right)$ removed the observed contrast.

\section{SUMMARY}

1. A $J_{c}$ of $1550 \mathrm{~A} / \mathrm{mm}^{2}$ at $10.5 \mathrm{~T}, 4.2 \mathrm{~K}$ was obtained using a new Nb-44 wt.\%Ti-17 wt.\%Ta alloy.

2. Inhomogeneous microstructures are typical of the ternary strands produced in this study.

3. The microstructure with the largest volume of fine intragranular precipitate produced the best $J_{\mathrm{c}}$ above $12 \mathrm{~T}(1.9 \mathrm{~K})$

4. $\mathrm{Nb}-44 \mathrm{wt} . \% \mathrm{Ti}-15 \mathrm{wt} . \% \mathrm{Ta}$ observed the previously reported linear relationship between volume $\% \alpha$-Ti precipitate and $J_{c}$ at $5 \mathrm{~T}$ and $8 \mathrm{~T}(4.2 \mathrm{~K})$ but with a lower rate of increase in $J_{\mathrm{c}}$ with precipitate volume than for $\mathrm{Nb}-47-\mathrm{wt}$.\% Ti.

5. The high atomic number contrast at the grain boundaries may be regions depleted in $\mathrm{Ti}$ because of the relatively fast transport of $\mathrm{Ti}$ along the grain boundaries compared with bulk diffusion through the grains. The contrast is also not inconsistent with Nb-rich "precipitation" regions observed recently by field ion microprobe [18]. We have also observed this contrast in heattreated $\mathrm{Nb}-\mathrm{Ti}$ strands and $\mathrm{Nb}-\mathrm{Ti}$ (Fe) [1]. $475^{\circ} \mathrm{C}$ heat treatment removed the grain boundary contrast.

\section{ACKNOWLEDGMENT}

We would also like to thank Steve Gourlay, now at LBNL, for his input for this project. James C. McKinnell, now at OI-ST, participated in the fabrication of the $\mathrm{Nb}-\mathrm{Ti}$ 15 Ta strands while at the UW.

\section{REFERENCES}

[1] P. J. Lee et al., "Development of High Performance $\mathrm{Nb}-\mathrm{Ti}(\mathrm{Fe})$ Multifilamentary Superconducting Strand for the LHC High Gradient Quadrupole Conductor. Paper MCA-01 at ASC'98, Palm Desert, CA, submitted for publication in IEEE Trans. Applied Superconductivity, September 15th, 1998.

[2] M. Suenaga, and K. M. Ralls, "Some superconducting properties of TiNb-Ta ternary alloys," J. Appl. Phys., vol. 40, pp. 4457-4463, 1971.

[3] D.G. Hawksworth, and D.C. Larbalestier, "Enhanced values of $\mathrm{Hc} 2$ in NbTi ternary and quaternary alloys," Adv. Cryo. Eng., vol. 26, pp. 479-486, 1980.

[4] H. R. Segal, T. M. Hrycaj, Z. J. J. Stekly, T. A. de Winter, and K. Hemachalam, "Nb-Ti based conductors for use in 12 Tesla toroidal field coils," in Proc. of 8th Symp. on Engineering Problems in Fusion Research, IEEE Pub. 79-CH-1441-5 NPS, pp.255-259, 1979.

[5] A. D. McInturff, J. Carson, D. C. Larbalestier, P. J. Lee, J. C. McKinnell, H. Kanithi, W. McDonald, P. O'Larey, "Ternary superconductor "NbTiTa" for high field superfluid magnets," IEEE Inter. Magnet Conf., Digest of Technical Papers, Brighton Polytechnic, U.K., p: AP15, 1990.

[6] B. G. Lazarev, O. V.Chernyj, G. E. Storozhilov, L. G.Udov, N. F. Andrievskaya, L. A. Kornienko, L. S. Lazareva, N. A. Chernyak, P. A. Kutsenko, B. K. Pryadkin, Y. A. D. Starodubov, M. B. Lazareva, V. M. Gorbatenko, "The Study Of The Microstructure And Jc In Nb-37Ti-22Ta Superconductor Produced With Different Duration Of Treatments," Proc. 7th Int. Workshop on Critical Currents in Superconductors, Alpbach, Austria, Ed. H. W. Weber, World Scientific Press, Singapore, pp. 601-604, 1994.

[7] P. J. Lee, J. C. McKinnell, and D. C. Larbalestier, Restricted Novel Heat Treatments for Obtaining High $J_{\mathrm{c}}$ in $\mathrm{Nb}-46.5 \mathrm{wt} \% \mathrm{Ti}$, Advances in Cryogenic Engineering (Materials), 36, pp. 287-294, 1990.

[8] P. J. Lee, J. C. McKinnell, and D. C. Larbalestier, "Restricted Novel Heat Treatments for Obtaining High $J_{\mathrm{c}}$ in Nb-46.5wt\%Ti: II. Prestrain Dependence," Adv. Cryo. Eng., vol. 40A, pp. 725-732, 1994.

[9] O. V. Chernyj, G. F. Tikhinskij, G. E. Storozhilov, M B. Lazareva, L. A. Kornienko, N. F. Andrievskaya, V. V. Slezov, V. V. Sagalovich, Ya D. Starodubov and S. I. Savchenko, Nb-Ti superconductors of a high currentcarrying capacity, Superconductor Science and Technology, 4, pp. 318323, 1991.

[10] P. J. Lee, D. C. Larbalestier, J. C. McKinnell and A. D. McInturff, "Microstructure property relationships in Nb-Ti-Ta," IEEE Transactions on Applied Superconductivity, vol. 3, pp. 1354-1357, 1993.

[11] R. Taillard, E. Florianova, C. E. Bruzek and Hoang-Gia-Ky, "Microstructure and Properties of Simultaneously Processed $\mathrm{Nb}-\mathrm{Ti}$ and $\mathrm{Nb}-\mathrm{Ti}-\mathrm{Ta} \mathrm{Su}-$ perconducting Wires," Adv. Cryo. Eng., Ed. L. T. Summers, Plenum Press, NY, vol. 42B, pp. 1151-1158, 1996.

[12]E. Gregory, T. Pyon, "Some properties of NbTiTa ternary alloys," Paper MCA-05 presented at ASC'98, Palm Desert, CA, submitted for publication in IEEE Trans. Applied Superconductivity, September 15th, 1998.

[13]P. J. Lee and D. C. Larbalestier, "An examination of the properties of SSC Phase II R\&D strands," IEEE Transactions on Applied Superconductivity, vol. 3, pp. 833-841, 1993.

[14]P. J. Lee, J. C. McKinnell, and D.C. Larbalestier, Microstructure Control in High Ti NbTi Alloys, IEEE Trans. on Magnetics, MAG-25, pp. 19181924, 1989.

[15] P. E. Danielson and D. B. Smathers, "Metallographic preparation of superconducting alloys and composites," Advances in Cryogenic Engineering, vol. 34, pp. 975-982.

[16] J. Parrell, P. Lee, and D. Larbalestier, "Cold work loss during heat treatment and extrusion of $\mathrm{Nb}-46.5 \mathrm{wt} \% \mathrm{Ti}$ composites as measured by microhardness," IEEE Transactions on Applied Superconductivity, vol. 3, pp. 734-737, 1993.

[17]M. I. Buckett and D. C. Larbalestier, "Precipitation at low strains in Nb46.5wt\%Ti," IEEE Trans. Mag., vol. 23, pp. 1638-1641, 1987.

[18] B. G. Lazarev, V. A. Ksenofontov, I. M. Mikhailovskii, O. A. Velikodnaya, "Nanostructure of superconducting Nb-Ti alloys," Low Temperature Physics, vol.24(3), pp.205-209, 1998. 